incurred risks by the gardeners in Ouagadougou, to bring them to adhere to the prevention strategies implemented for their health and safety.

Methods It was a descriptive and cross-sectional study. The study population consisted of 101 gardeners coming from three districts. They were involved in a no probabilistic way by a systematic recruitment.

Results Most of gardeners were illiterate (66.3\%). Their ages ranged between 21 and 69 years old, with a median of 38 years. $78.2 \%$ of gardeners have been trained once on pesticides. Most of the vegetable growers used mainly pyrethroids $(86 \%)$ as pesticide. More than $90 \%$ of gardeners apply products by spraying and they keep the stocks in the fields. Personal Protective Equipment (PPE) was not worn. The empty containers were either buried in the ground or thrown into the fields. The respiratory tract irritation, respiratory difficulties, eyes irritation, and headache were the dominant symptoms after pesticide application. The drinking water came from wells not well covered in majority.

Conclusion With the strong urbanisation and the increase of the demand, the gardeners were taken to big use of pesticides most of the time without follow-up nor control, with all the possible risks for their health, those of the populations as well as for the environment.

\section{CROSS-SECTIONAL SURVEY ON GENITOURINARY SYSTEM HEALTH OF VEGETABLE GREENHOUSE GROWERS IN SUBURBAN AREAS IN YINCHUAN}

Jian Zhou, Xiao-Yu Zhi, Li-Jun Dong, Min Xue, Ling-Qin Zhu, Jiang-Ping Li, Hong-Hui Li, Somen Palit, Min Huang, Da-Nian Tian, Hui-Fang Yang. Ningxia Medical University, Yinchuan, People's Republic of China

\subsection{6/oemed-2018-ICOHabstracts. 1361}

Introduction China has the largest greenhouse production area in the word, with the rapid development of Ningxia facility agriculture, some greenhouse growers use the pesticides blindly in order to eliminate pests and increase economic efficiency. However, they are lack of the knowledge about how to use the pesticides and the individual protection consciousness of them are not high. We need to evaluate the genitourinary system health of vegetable greenhouse growers and analyse related influencing factors so as to protect these occupational population and improve their health.

Methods Adopted the methods of whole group sampling at random studied on vegetable greenhouse growers in three districts and two countries of suburb in Yinchuan, collected the basic information and the pesticide exposure intensity by questionnaire. Used the logistic regression analytic method to each factor, found the influencing factors of the current state of genitourinary system in vegetable greenhouse growers, during April 2015 to May.

Results In this study, 207 females and 241 males vegetable greenhouse growers were selected, the valid questionnaire return rate was $97.4 \%$. The genitourinary system prevalence rate reached $75.8 \%$ in the female growers. The results of multiple logistic regression analysis showed that increased the frequency of crop-spraying $(\mathrm{OR}=3.683)$ and chatting during crop-spraying $(\mathrm{OR}=2.532)$ were risk factors, while using abamectin $(\mathrm{OR}=0.311)$ was a protective factor. The genitourinary disease prevalence rate was only $14.11 \%$ in the male growers. The results showed that the risk factors of male genitourinary system health included age $(\mathrm{OR}=1.048)$, pesticides exposure classification $(\mathrm{OR}=5.11)$, types of mixed pesticides $(\mathrm{OR}=3.243)$, and the proportion of mixed pesticides $(\mathrm{OR}=0.697)$. The frequency of eating meat per week $(\mathrm{OR}=0.697)$ was the protective factor.

Conclusion A higher prevalence rate of genitourinary diseases was found in female vegetable greenhouse growers in Yinchuan. Deficiency the correct pesticides use and the related protective measures are the main influencing factors.

\section{OCCUPATIONAL EXPOSURE TO PESTICIDES AMONG FARMERS: OUTCOMES OF SURVEY AND LEADS FOR PREVENTION}

1,2,3 Y Moreau $^{*}$ 1,2,3 A-S Lacauve, $1,2,3 \mathrm{~S}$ Deant, ${ }_{1,2,3} \mathrm{~V}$ Tribouillard, ${ }^{1,2,3} \mathrm{~N}$ Lévèque-Morlais, ${ }^{1,2,3} \mathrm{~S}$ Perrier, ${ }^{1,2,3} \mathrm{C}$ Lailler, ${ }^{1,2,3} \mathrm{~L}$ Faion, ${ }^{1,2,3} \mathrm{~V}$ Lambert, ${ }^{1,2,3} \mathrm{Y}$ Lecluse, ${ }^{4} \mathrm{~T}$ Apostolidis, 1,2,3P Lebailly. 'Centre François Baclesse, Caen, France; ${ }^{2}$ UMR 1086 Inserm Anticipe Axe Cancers and Préventions, Caen, France; ${ }^{3}$ Université de Caen Normandie, Caen, France; ${ }^{4}$ Laboratoire de Psychologie Sociale, Aix-Marseille Université, Aix en Provence, France

\subsection{6/oemed-2018-ICOHabstracts. 1362}

Introduction Farmers are particularly exposed to pesticides while performing their professional tasks. In France, Certiphyto training program is aiming to decrease occupational exposure by improving knowledge.

Several studies have shown the importance of the following two aspects, which are not taken into account by Certiphyto: psychosocial factors such as risks perceptions, peer norms, self-efficacy are important to better understand the underlying mechanisms of occupational exposure to pesticides among farmers; alternative educational strategies such as prevention by peers and practical exercises.

Methods We have conducted a national telephone survey among 197 farmers from three agricultural settings (open-field, open-field - cattle-breeding, viticulture) and we also realised an ergonomic and psychosocial analyse of Certiphyto by observation of sessions and semi-structured interview of trainers.

Results Direct exposure, studied by descriptive and comprehensive approach with determinants - frequency of Personal Protective Equipment (PPE) and adequacy with recommendations, hygiene habits, level of knowledge and psychosocial factors - is analysed in a comparative inter-setting perspective, indirect exposures, in an exploratory approach.

Our results show that, among pesticide users, PPE use is weak but for gloves during preparation phase $(60 \%$ of users use gloves systemically, $30 \%$ do not always use another PPE), and therefore insufficient according to recommendations. In addition, hygiene habits are also insufficient, both hygiene and PPE compliance being variable between agricultural settings. Similar observations have been made for indirect exposure. Analysis of psychosocial determinants highlights several obstacles for PPE use, among which discomfort of using PPE for specific task and peer norms. We also show persistence of inadequate habits and false knowledge after Certiphyto.

Conclusion We identified leads for the design of an alternative Certiphyto training including practical exercises and intervention of farmers peers. This prevention program, in design phase, will take into consideration psychosocial factors, specially risk perception, peer norms and health locus of control on developing psychosocial strategy. 